\title{
Prostatic Utricle
}

National Cancer Institute

\section{Source}

National Cancer Institute. Prostatic Utricle. NCI Thesaurus. Code C63862.

A small indentation located in the prostatic urethra, at the apex of the urethral crest, on the seminal colliculus, laterally flanked by openings of the ejaculatory ducts. 